\title{
Individual Participant Data Meta-Analysis of Foliar Fungicides Applied for Potato Early Blight Management
}

\author{
S. K. R. Yellareddygari, Julie S. Pasche, Raymond J. Taylor, and Neil C. Gudmestad, Department of Plant Pathology, North Dakota State \\ University, Fargo 58105
}

\begin{abstract}
Yellareddygari, S. K. R., Pasche, J. S., Taylor, R. J., and Gudmestad, N. C. 2016. Individual participant data meta-analysis comparison of foliar fungicides applied for potato early blight management. Plant Dis. 100:200-206.

Foliar fungicides continue to be the primary means of early blight management on potato in the United States. Both premium-priced, single-site mode-of-action "specialty" fungicides and standard protectant multisite fungicides are applied, either alone or incorporated into fungicide rotation programs to combat early blight. Individual participant data meta-analysis was conducted to compare overall fungicide efficacy against early blight on potato, quantify tuber yields, and identify the most efficacious timing for fungicide applications. In this study, the specialty fungicide-based applications were compared against the standard fungicides chlorothalonil and mancozeb applied alone. Type 3 fixed effects

indicated that there was a significant difference $(P<0.0001)$ in overall efficacy and yield among the treatments applied to manage early blight in potato. There was a significant difference $(P<0.0001)$ among treatments in early blight development during the growing season. Applications incorporating specialty fungicides, when compared with standard fungicides, significantly affected disease severity from vegetative growth initiation $(P=0.0139)$ to tuber maturation $(P=0.0009)$. Results demonstrate that the higher cost, specialty-fungicide-based applications were most effective for early blight management in North Dakota and Minnesota.
\end{abstract}

Potato (Solanum tuberosum L.) is the most important of the root and tuber crops grown and is consumed all over the world. Early blight, caused by Alternaria solani Sorauer, is a major foliar pathogen affecting potato cultivation worldwide (Harrison and Venette 1970). The pathogen produces distinct small, dark concentric ringlike foliar lesions diagnostic of the disease (Franc and Christ 2001; Gudmestad et al. 2013). Lesions also may develop on petioles and stems. Infections usually occur first on the lower, more mature leaves near the base of the plant and eventually move to the upper canopy as the disease progresses. In severe cases, leaves become chlorotic and eventually necrotic, severely restricting photosynthetic capacity and markedly impacting yield. Various environmental factors working independently or together may affect disease development and pathogen spread. Temperature, rainfall, relative humidity, or alternate dry and wet conditions influence early blight development and outbreaks (Olanya et al. 2009). If left nontreated, A. solani can cause severe quality and yield losses (Franc and Christ 2001; Olanya et al. 2009).

Potato is a high-value crop and maximizing productivity per hectare through crop protection is an important management strategy for growers. Fungicides are used extensively to manage early blight due to the current lack of other durable, effective disease control methods such as cultivar resistance (Gudmestad et al. 2013). Several fungicides which differ by mode and site of action are available for early blight control. Standard fungicides such as chlorothalonil and mancozeb are applied extensively by potato growers for early blight and late blight (Phytophthora infestans (Mont.) de Bary) suppression (Gudmestad et al. 2013; Holm et al. 2003). Standard fungicides are usually less expensive and have a low risk of resistance development because they affect the function of multiple metabolic pathways within fungi and fungal-like organisms. However, these fungicides have been reported to be less effective under intense disease pressure conditions (Gudmestad et al. 2013; Pasche and Gudmestad 2008).

Corresponding author: N. C. Gudmestad; E-mail: neil.gudmestad@ndsu.edu Accepted for publication 20 July 2015.

http://dx.doi.org/10.1094/PDIS-05-15-0530-RE

(C) 2016 The American Phytopathological Society
At present, single-site specific mode-of-action fungicides are the preferred and most widely used chemistries for early blight control (Pasche and Gudmestad 2008). Site-specific fungicides, hereafter referred to as "specialty" fungicides, are effective against leaf spot diseases of potato but lack the broad-spectrum activity of standard fungicides that also control other foliar diseases such as late blight. After registration for use in potato, quinone outside-inhibitor (QoI) fungicides such as azoxystrobin and pyraclostrobin and succinate dehydrogenase inhibiting (SDHI) fungicides such as boscalid were often used successfully to manage early blight in the United States (Pasche and Gudmestad 2008; Stevenson and James 1999). However, mutations that confer resistance to these fungicides have been detected in A. solani, rendering them ineffective for the management of early blight in the United States (Gudmestad et al. 2013; Mallik et al. 2014; Pasche and Gudmestad 2008; Pasche et al. 2004). From a management standpoint, the problem facing growers is whether and when it is practical to utilize premium-priced single-site fungicides instead of standard multisite fungicides. Because of this, a comparison of the degree of efficacy of these types of fungicides under field conditions would be beneficial to potato growers. Individual fungicide efficacy trials can provide some basic data; however, to obtain the maximum amount of useful information, any such study should include multiple observations from several studies over multiple years and locations. Meta-analysis (MA) is an ideal statistical tool for combining and synthesizing results or findings from studies with similar objectives.

Most fungicide field trials are conducted as individual studies, where complex interactions occur among treatments, cultivars, pathogens, and environmental factors. Due to this, unknown variation is often included in research results and inadequate conclusions can be drawn if such variability is not accounted for (Kiær et al. 2006). MA allows investigators to combine results from independent studies to obtain a standardized composite estimate of treatment effect size (Means et al. 2009). It incorporates the treatment responses across studies and differences in the treatment effects for each study (Riley et al. 2010). MA is a statistically reliable tool for combining results from multiple studies having similar research objectives (Madden and Paul 2011; Nelson et al. 2015; Ngugi et al. 2011). Application of MA in plant pathology has increased in the past 5 years, especially in fungicide efficacy studies (Madden and Paul 2011; Ngugi et al. 2011). 
The use of individual participant data (IPD), where raw data from multiple studies is obtained for the similar response of interest and used for the synthesis, is a popular MA approach (Riley et al. 2010; Stewart and Parmar 1993; Sung et al. 2014). IPD is considered a gold standard over the traditional MA of data extracted from research publications (Thomas et al. 2014). Advantages of IPD include access to the original source of data, detailed data checking, reduced statistical heterogeneity across studies, and estimate subgroup analysis (Pufulete et al. 2014). Subgroup analysis refers to separating the participant data into subsets to make comparisons between them. However, obtaining raw data is challenging, expensive, time consuming, and limited in terms of the number of studies accommodating similar research objectives (Sung et al. 2014). Comprehensive advantages and disadvantages of IPD have been described (Stewart and Tierney 2002).

Raw data can be synthesized using a one- or two-stage approach of IPD. During two-stage IPD-MA, the data of each individual trial are analyzed separately and, later, summary statistics from the primary analysis are combined for synthesis using the appropriate MA method. When using the one-stage approach, data from all individual studies are simultaneously modeled while accounting for clustering of participants within studies (Riley et al. 2010). Both approaches have merits and, when heterogeneity among trials is large and the number of trials included in the study is small, the one-stage IPD-MA approach is more appropriate (Ahmed et al. 2012; Nelson et al. 2015; Stewart et al. 2012).

In the current study, IPD-MA was performed to estimate disease and yield responses to specialty fungicides incorporated into management programs compared with standard fungicides. The research objectives were to (i) determine the overall efficacy of specialty fungicide-based application programs and standard fungicides with respect to early blight control and tuber yield response and (ii) identify a timeline for the application of programs incorporating specialty fungicides and standard fungicides for the control of early blight during the growing season.

\section{Materials and Methods}

Field trials: inoculation, fungicide application, and disease assessment. This analysis incorporates data collected from 12 field trials conducted from 2003 to 2014 in North Dakota and Minnesota. These trials were conducted to determine the efficacy of fungicides for the control of early blight on potato. The early blight susceptible 'Russet Burbank' potato was planted during the 2003 and 2007 growing seasons near Tappen, ND and 2004, 2005, and 2006 growing seasons near Browerville, MN. Susceptible 'Ranger Russet' was planted in the 2008, Tappen, ND field trial and from 2009 to 2014 in trials established near Inkster, ND. The experimental plot design for each trial was a randomized complete block design (RCBD) with four replications. Hand-selected and cut seed tubers were planted $0.4 \mathrm{~m}$ apart in each plot. Each individual plot comprised four rows, $9.1 \mathrm{~m}$ long by $0.9 \mathrm{~m}$ wide, except in the 2003 trial, where seed tubers were planted in rows of 7.6 by $0.9 \mathrm{~m}$. The plots were irrigated as needed using an overhead sprinkler irrigation system. Emergence data were recorded, and necessary fertilizer and pesticide sprays were applied during each crop growing season to manage weed and insect pests, according to common agronomic practices used in North Dakota and Minnesota (Bohl and Johnson 2010).

Depending on individual study research goals, specific A. solani isolates were selected for artificial inoculation. Selected isolates of A. solani were recovered from long-term cryogenic storage and plated on clarified V8 medium (V8 juice, $100 \mathrm{ml}$; $\mathrm{CaCo}_{3}, 1.5 \mathrm{~g}$; agar, $15 \mathrm{~g}$; and distilled water, $900 \mathrm{ml}$ ) as described (Pasche et al. 2004). Cultures were grown under constant fluorescent light for 1 to 2 weeks at $22 \pm 2{ }^{\circ} \mathrm{C}$. Conidia were freed from the media under aseptic conditions using sterile glass rods and distilled water. Conidial concentration of the final inoculum suspension was adjusted to desired levels using a hemocytometer. For any trial, a conidial suspension of approximately $3 \times 10^{5}$ conidia/ml was applied twice at the rate of 100 to $125 \mathrm{ml} /$ row (1 month after planting and 2 weeks after initial spray) during the growing season. A handheld $\mathrm{CO}_{2}$ sprayer was used to dispense the suspension on the two outer rows of each plot. Prior to 2005, wildtype isolate 13-1 was used to inoculate the field trials. From 2005 through 2014, a 50:50 mixture of 13-1 and QoI-resistant isolate 526-3 was used to inoculate the field trials. These two isolates were determined previously to possess equal aggressiveness in causing early blight on nonfungicide-treated tomato plants (Pasche and Gudmestad 2008).

Fungicide treatments were applied to four rows using a converted ATV with modified spray equipment delivering 0.5 to $0.7 \mathrm{~m}^{3} / \mathrm{ha}$ at 413.7 to $448.2 \mathrm{kPa}$ pressure through $11005 \mathrm{XR}$ nozzles. Depending on planting dates, the first treatments were applied between late June and early July and continued at 7-day intervals for the remainder of the growing season (mid- to late September). Five weeks after planting, early blight severity was visually estimated on a weekly basis for 11 weeks during all 12 years by one of the authors (R. J. Taylor). Disease was assessed during periods representing three phases of potato development: the vegetative growth and flowering stage (approximately week 1 to 4 ), tuber initiation and bulking (week 5 to 9), and tuber maturation (week 10 to 11). Disease severity was evaluated only on the two middle rows of each four-row plot while the outside bordered rows and row edges were ignored to minimize interplot interference. Severity was assessed on $1^{2}$-m sampling areas as the percentage of foliage showing chlorotic or necrotic lesions and senescent foliage typical of $A$. solani infections. Foliar ratings were taken approximately $1 \mathrm{~m}$ from the beginning and $1 \mathrm{~m}$ from the end of the paired center rows and at two additional locations, between and approximately equidistant from these first and last assessment sites. At the time of each assessment, 4 disease severity observations were made per experimental unit equating to 16 observations/treatment. The potato vines were removed at the end of the growing season by means of a mechanical rotobeater and tubers were harvested from middle rows of each plot from which total yield was recorded.

Treatment types. Fungicide rate, application schedule, and active ingredient varied among studies. However, only trials including a specialty (single-site, specific mode-of-action) fungicide, standard protectant (multisite activity) fungicide, and a nonfungicide-treated check were eligible for IPD-MA (Table 1). Furthermore, specialty fungicides were separated based on QoI and SDHI group chemicals applied in rotation with other fungicide classes and, henceforth, will be referred to as group 1 and group 2 specialty fungicides, respectively. In this study, the two specialty groups were (i) QoI fungicide applied in rotation with anilinopyrimidines, representing FRAC codes 11 and 9, respectively; and (ii) SDHI applied in alternation with QoI or triazoles, representing codes 7 , and 11 or 3 , respectively (Table 1 ). Specialty fungicides were rotated with standard fungicides at a 2:3 ratio and applied over the growing season. They were compared against the standard fungicides applied alone, such as chlorothalonil and mancozeb, grouped in FRAC class M5 and M3, respectively (Table 1). All fungicide applications were initiated before the onset of the disease during the mid-vegetative-growth stage and, in total, 10 foliar fungicide applications were made throughout the growing season at 7-day intervals.

Data collection and analysis. Overall, 8,448 disease severity data points and 384 yield responses were collected and analyzed over 12 years of field trials. All trials satisfied the criteria of having a similar experimental design (RCBD), treatment types, number of replications (four), and common research objective. Data from the 12 experiments were pooled per trial, treatment, replication, and response variables. All data from individual trials underwent meticulous reviewing of the treatment groups of interest. For this analysis, treatments were fixed, and trial, block, and treatment-trial interactions were random and continuous across studies. The primary outcomes of overall efficacy of disease control and yield responses due to fungicide applications were estimated. Furthermore, MA was used to estimate the effect of fungicides on percent early blight severity as multiple outcomes (for each week separately) over the cropgrowing season. For example, if the expectation is that the fungicide effect on overall disease severity could vary by crop season, it is possible to report the effect separately for multiple time points within the study. 
The experimental field data were skewed when combined and compared across studies. For example, the normality assumption is violated because a histogram plot shows that the data are highly right skewed (Fig. 1A). To resolve this skewness, a logarithm transformation was applied to the raw data to obtain a continuous linear distribution (Fig. 1B). The normality and homogeneity of variance assumptions were also tested. Early blight severity among treatments and trials is not uniform and few (23 occurrences during vegetative growth) data points representing zero disease severity were measured. However, there were no negative or zero values recorded in tuber yield response to fungicide applications. Disease severities that included zeros were treated as a missing value during log transformation (O'Hara and Kotze 2010). IPD analysis was performed with the scale of log-transformed data and, unless otherwise stated, the results presented in this study are on a log scale. For example, new response $h$ on $\log$ scale is equal to $\log _{\mathrm{e}} \mathrm{y}$, where $y$ represents the prior $\log$ transformed response.

In field studies, even after controlling the factors of interest for analysis, there may be substantial variation among response variables and an appropriate model should be used. A mixed-effect model is considered most suitable because it includes intertrial variation in the uncertainty of response parameters (Konstantopoulos 2006). A mixed-effect analysis of variance model assuming a common intercept $\pi$ for all trials, a random trial effect across studies, intrastudy variance of each trial, and intertrial heterogeneity was designed for this study. The model used in the present study is similar to another mixed-effect model fungicide efficacy study (Nelson et al. 2015):

$$
X i j k=\pi+\alpha_{i}+\beta_{j}+(\alpha \beta)_{i j}+\gamma(\beta)_{j k}+\xi_{i j k}
$$

where Xijk is the observation for treatment $i(i=1, . ., a)$ in block $k$ for trial $j(j=1, . ., n), \pi$ is the common intercept across all studies, $\alpha i$ is the effect of treatment, $\beta j$ is the effect of trial, $(\alpha \beta) i j$ is the effect of interaction between treatment $i$ and trial $j$, and $\gamma(\beta) j k$ is the random effect of block $k$ in trial $j$. The parameter $\xi i j k$ is the residual error for treatment $i$ in block $k$ of trial $j$. It is assumed that covariates (trial and block) and trial-treatment interactions have random effects and account for intra- and interstudy variance. The residual error is random and independent across studies.

Repeated-measure analysis was performed to analyze 11 weekly disease assessments as a function of assessment time (week) and time-treatment interaction:

$$
X i j k=\pi+\alpha_{i}+\beta_{j}+(\alpha \beta)_{i j}+\gamma(\beta)_{j k}+\theta_{l}+(\alpha \theta)_{i l}+\xi_{i j k l}
$$

where $\theta_{l}$ is the effect of weekly assessment, $(\alpha \theta)_{i l}$ is the effect of interaction between treatment $i$ and weekly assessment $l$, and $\xi i j k l$ is the residual error for treatment $i$ in block $k$ of trial $j$ for week $l$. The weekly assessment and its interaction with treatment are fixed effects in the model.

The primary point of interest in this analysis is the difference among the treatments; therefore, treatments are considered to be a fixed effect and their effect varies randomly across trials. Because the model contains both fixed and random effects, a mixed model is appropriate for IPD analysis. To fit a mixed model, SAS PROC Mixed was used in this analysis (SAS codes will be provided upon request). Based on the result from an $F$ test (type 3 tests of fixed effects), if the $P$ value is less than the significance level (0.05), a multiple comparison (pairwise) using the Tukey-Kramer method was conducted. Tukey-Kramer test controls family-wise error rate; therefore, adjusted $P$ value is used to compare the significance level. Type 3 sum of squares were used for unbalanced data due to the interaction term in the study model. Also, PROC Mixed was used for repeatedmeasure analysis of disease severity over 11 weeks. SAS PROC Univariate was used to test the normality assumption and PROC GLM for testing homogeneity of variance assumption for transformed data.

\section{Results}

Overall fungicide efficacy. Overall effect of treatment on early blight severity was statistically significant $(F$ value $=26.59, P<$ $0.0001)$. Significant differences were observed among all treatments with a pairwise comparison test, except between specialty fungicides (Table 2). Mean overall early blight averaged across 11 -week assessments in nontreated plots averaged $74 \%$ over the 12 -year study period. Overall, mean early blight severities averaged across 11-week assessments were 43 and $45 \%$ for plants treated with group 1 and group 2 specialty fungicides, respectively. Greater percentages (54\%) of early blight were observed for standard protectant fungicide treatments. Compared with the standard fungicide application, the mean percent decrease in early blight with group 1 and group 2 specialty fungicides was 30 and $28 \%$, respectively.

Fungicide efficacy during the crop growing season. Repeatedmeasure analysis for early blight severity assessment time (week) showed that the treatments were significant $(P<0.0001)$ and the

\begin{tabular}{|c|c|c|c|c|}
\hline $\begin{array}{l}\text { Treatment group (number of trials), } \\
\text { chemical group }^{\mathbf{b}}\end{array}$ & FRAC group & Active ingredient & Trade name & Rates \\
\hline \multicolumn{5}{|l|}{ Specialty fungicide group 1 (12) } \\
\hline Methoxy-carbamates & 11 & Pyraclostrobin & Headline & 0.65 liter/ha \\
\hline Oxazolidine-diones & 11 & Famoxadone & Tanos & 0.42 liter/ha \\
\hline Imidazolinones + & 11 & Fenamidone & Reason & $0.28-0.5$ liter/ha \\
\hline Anilino pyramidines + & 9 & Pyrimethanil & Scala & 0.49 liter/ha \\
\hline Choloronitriles, dithio-carbamates & $\begin{array}{c}\text { M5, M3 } \\
\quad \ldots\end{array}$ & $\begin{array}{c}\text { Chlorothalonil, mancozeb } \\
\ldots\end{array}$ & $\begin{array}{l}\text { Echo } \\
\text { Dithane }\end{array}$ & $\begin{array}{l}2.5 \text { liter/ha, } \\
2.24 \mathrm{~kg} / \mathrm{ha}\end{array}$ \\
\hline \multicolumn{5}{|l|}{ Specialty fungicide group 2 (12) } \\
\hline Pyridine carboxamides & 7 & Boscalid & Endura & $0.18-0.21$ liter/ha \\
\hline Pyridinyl-ethylbenzamides, & 7 & Fluopyram & Luna Tranquility & 0.65 liter/ha \\
\hline Anilino pyramidines + & 9 & Pyrimethanil & Scala & 0.5 liter/ha \\
\hline Triazoles + & 3 & Difenoconazole & Revus top & 0.5 liter/ha \\
\hline Methoxy-carbamates + & 11 & Pyraclostrobin & Headline & 0.65 liter/ha \\
\hline Choloronitriles, dithio-carbamates & M5, M3 & Chlorothalonil, mancozeb & Echo & 2.5 liter/ha, \\
\hline & $\ldots$ & $\ldots$ & Ditahne & $2.24 \mathrm{~kg} / \mathrm{ha}$ \\
\hline \multicolumn{5}{|l|}{ Standard fungicides (12) } \\
\hline Chloronitriles & M5 & Chlorothalonil & Bravo, Echo & 1.8-2.5 liter/ha, 2.5 liter/ha \\
\hline Dithio-carbamates & M3 & Mancozeb & Dithane & $2.24 \mathrm{~kg} / \mathrm{ha}$ \\
\hline Nontreated check (12) & $\ldots$ & $\ldots$ & $\ldots$ & $\ldots$ \\
\hline
\end{tabular}

Table 1. Treatment list for field trials evaluating fungicide efficacy for potato early blight control in North Dakota and Minnesota from 2003 to $2014{ }^{\text {a }}$ 
time-treatment interaction effect was also significant $(P<0.0001)$. When 11 weekly assessments were considered independently and MA was fitted to each week, there was a significant difference $(P<0.0001)$ among treatments in early blight development during the growing season (Table 3 ). In the nontreated plants, mean early blight severity ranged from 1 to $74 \%$ through the growing season. In specialty and standard fungicide-treated plants, mean disease severity ranged from 0 to $45 \%$ and 1 to $54 \%$, respectively. Both group 1 and group 2 specialty fungicides showed significant suppression of early blight when compared with standard fungicides at tuber initiation $(P=0.0018)$ and the tuber bulking crop growth stages $(P=0.0009)$. Group 2 specialty fungicides, when compared with standard fungicides, differed significantly from vegetative growth initiation $(P=0.0139)$ to the maturation of tubers $(P=$ $0.0009)$. Significant differences in early blight control also were observed between group 1 specialty fungicides and standard fungicides from tuber initiation $(P=0.0018)$ and bulking to maturation of tubers $(P=0.0395)$. Standard fungicides provided a significant level of control in managing early blight during tuber initiation and bulking of potato compared with the nontreated control $(P=0.0076$; Figs. 2 and 3$)$. Compared with nontreated plots, specialty fungicide programs provided significant control during all stages of potato growth and nearly all individual weekly time points (Table 3). However, at any given crop growth stage, there was no significant difference between the two groups of specialty fungicides.

Aggregated potato yield response to fungicide application. Type 3 fixed effects demonstrated significant differences $(F$ value $=15.59, P<0.0001)$ in yield among the treatments applied for early blight management in potato. Over the 12-year study period, the total yield response to treatments ranged from 55 to $88 \mathrm{t} / \mathrm{ha}$. Results for pairwise comparison of yield response were similar to those observed for percent disease severity where differences between the specialty fungicides were not

Table 2. Pairwise comparison of treatments for potato early blight percentage disease severity and yield response compared across 12 trials $^{\mathrm{a}}$

\begin{tabular}{llcc}
\hline Treatment 1 & \multicolumn{1}{c}{ Treatment 2 } & $\begin{array}{c}\text { Adjusted } \boldsymbol{P} \\
\text { for disease } \\
\text { severity }\end{array}$ & $\begin{array}{c}\text { Adjusted } \\
\boldsymbol{P} \text { for yield } \\
\text { response }\end{array}$ \\
\hline Specialty fungicide 1 & Specialty fungicide 2 & 0.9991 & 1 \\
Specialty fungicide 1 & Standard fungicide & 0.0074 & 0.0339 \\
Specialty fungicide 1 & Nontreated & $<0.0001$ & $<0.0001$ \\
Specialty fungicide 2 & Standard fungicide & 0.0051 & 0.0321 \\
Specialty fungicide 2 & Nontreated & $<0.0001$ & $<0.0001$ \\
Standard fungicide & Nontreated & 0.0013 & 0.028 \\
\hline a Except for specialty fungicide 1 versus specialty fungicide 2 comparison, all \\
treatment 1 versus treatment 2 comparisons showed significant difference \\
$\begin{array}{l}P<0.05) . P \text { values } \\
\text { Spece obtained following Tukey-Kramer adjustment. }\end{array}$ \\
2:3 ratio and applicides were used in combination with standard fungicides at \\
\end{tabular}

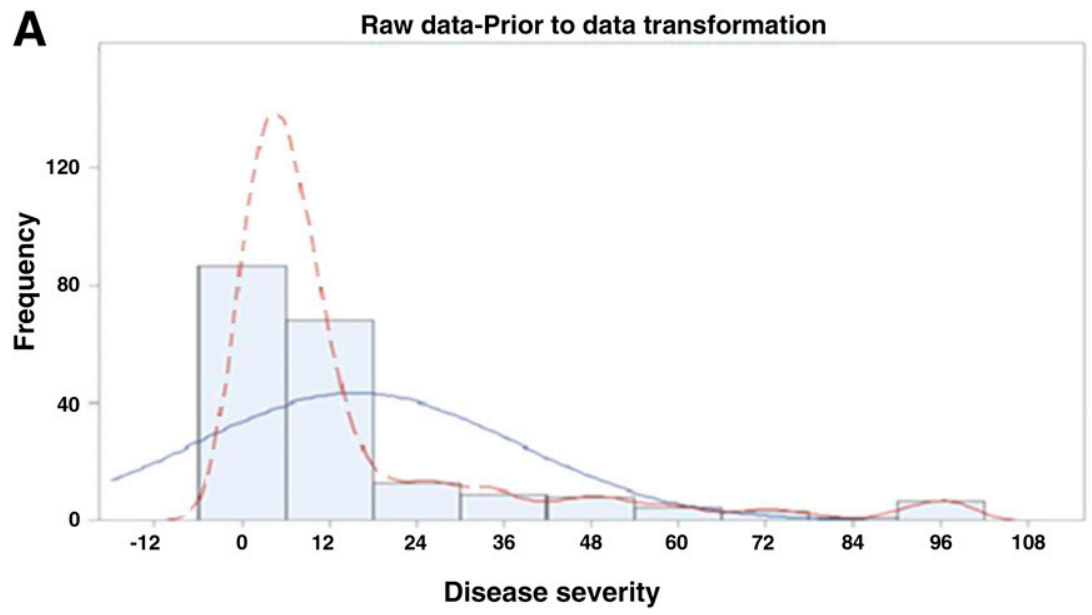

B

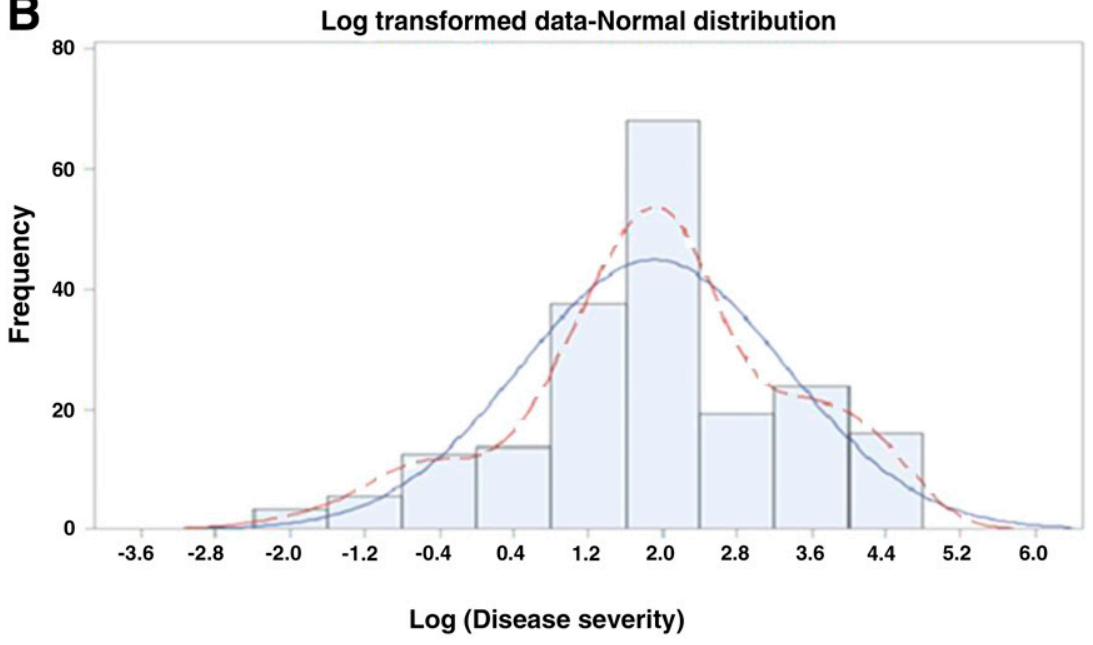

Fig. 1. Example of data distribution for percent severity of early blight on potato measured during week 8 of the crop growing season. A, Distribution of raw data for disease severity during week 8. B, Week 8 data after log transformation satisfying the normal distribution assumption. The y axis represents frequency. The dashed line is the reference line from data density and the solid line represents the normal curve used to compare with the reference lines. $P$ value for Kolmogorov-Smirnov normality test is 0.052 and Levene's test for homogeneity is 0.4299 . 
observed but significant variation among other treatments was observed (Table 3 ). The mean yield estimates for specialty 1 , specialty 2, standard, and control treatments were 60.2, 60.1, 57.5 , and $55.0 \mathrm{t} / \mathrm{ha}$ respectively.

\section{Discussion}

Reported in this study were the results from the first attempt to meta-analyze raw data obtained from individual multiple-year and multiple-location field trials performed to evaluate foliar fungicide treatment programs for the management of early blight of potato. IPD-MA was used to interpret data collected for field efficacy of selected fungicide treatments applied to control this foliar leaf spot disease from 2003 to 2014. Increased yield responses were obtained with early blight suppression when specialty and standard fungicide chemistries were applied. Furthermore, this study identifies a time point during the growing season when specific fungicide applications were found to be most effective against early blight.

Traditionally, potato early blight control has been achieved with intensive application of protectant fungicides chlorothalonil or mancozeb. Foliar fungicide applications are usually initiated before disease inception and applied every 7 to 10 days throughout the growing season to suppress pathogen development and establishment. On the basis of our analysis, disease control provided by these standard protectant fungicides significantly reduced overall disease severity (34\%) when compared with the nontreated control. This highpercentage foliar disease control demonstrates the importance of fungicide applications for early blight management in potato (Gudmestad et al. 2013; Holm et al. 2003; Pasche et al. 2004). Potato growers in North Dakota and Minnesota have been concerned that standard fungicides applied alone do not necessarily guarantee adequate protection against early blight epidemics in growing seasons conducive to disease development (Holm et al. 2003). High disease pressure based on the environmental differences from year to year is one reason that potato growers have incorporated more expensive single-site specialty fungicides into their foliar disease management programs.

Since 1990, costs of managing early blight have continued to increase as new site-specific fungicides have entered the marketplace (Stevenson et al. 2007). Novel single-site fungicides were successful upon introduction but did not endure because of rapid development of fungicide resistance in A. solani (Gudmestad et al. 2013; Mallik et al. 2014; Pasche and Gudmestad 2008; Pasche et al. 2004). QoI fungicides were first registered on potato in 1999 but resistance developed in the early blight fungus by 2001 (Pasche and Gudmestad 2008; Pasche et al. 2004). SDHI fungicides were registered on potato in 2005 and resistance in A. solani became prevalent by 2010 (Gudmestad et al. 2013). Despite reports of reduced efficacy due to

Table 3. Significance level ( $P$ value) from individual participant data meta-analysis for potato early blight percent disease severity measured across 11 weeks of data observed (w1 through w11) during crop growth ${ }^{\mathrm{a}}$

\begin{tabular}{|c|c|c|c|c|c|c|c|c|c|c|c|c|}
\hline \multirow[b]{2}{*}{ Treatment 1} & \multirow[b]{2}{*}{ Treatment 2} & \multicolumn{4}{|c|}{ Vegetative growth and flowering } & \multicolumn{5}{|c|}{ Tuber initiation and bulking } & \multicolumn{2}{|c|}{ Tuber maturation } \\
\hline & & $\log w 1$ & $\log w 2$ & $\log w 3$ & $\log w 4$ & $\log w 5$ & $\log w 6$ & $\log w 7$ & $\log w 8$ & $\log w 9$ & $\log w 10$ & $\log w 11$ \\
\hline Specialty 1 & Specialty 2 & 0.752 & 0.033 & 0.219 & 0.422 & 0.233 & 0.09 & 0.776 & 0.24 & 0.995 & 0.996 & 0.984 \\
\hline Specialty 1 & Standard & 0.996 & 0.998 & 1 & 0.232 & 0.393 & 0.804 & 0.052 & 0.029 & 0.002 & 0.04 & 0.054 \\
\hline Specialty 1 & Nontreated & 0.997 & 0.661 & 0.437 & 0.003 & 0.008 & 0.001 & 0.0001 & 0.0001 & 0.0001 & 0.0001 & 0.0001 \\
\hline Specialty 2 & Standard & 0.561 & 0.014 & 0.210 & 0.01 & 0.007 & 0.011 & 0.005 & 0.000 & 0.001 & 0.064 & 0.115 \\
\hline Specialty 2 & Nontreated & 0.822 & 0.002 & 0.009 & 0.0001 & 0.0001 & 0.0001 & 0.0001 & 0.0001 & 0.0001 & 0.0001 & 0.000 \\
\hline Standard & Nontreated & 0.969 & 0.723 & 0.481 & 0.277 & 0.274 & 0.008 & 0.001 & 0.0001 & 0.004 & 0.053 & 0.073 \\
\hline
\end{tabular}

a Two study treatments were compared for 11 weeks during the growing season. Special 1 and Special $2=$ specialty fungicides 1 and 2; respectively, and Standard $=$ standard fungicide. The $P$ value indicates whether the compared treatments were significant (bold) or nonsignificant during the course of crop growth. Log represents $P$ values for log-transformed data. The foliar disease observed during this time period represents three phases of potato development: vegetative growth and flowering stage (week 1 to 4 ), tuber initiation and bulking (week 5 to 9), and maturation of tubers (week 10 to 11). Specialty fungicides were used in combination with standard fungicides at 2:3 ratio and applied over the growing season.
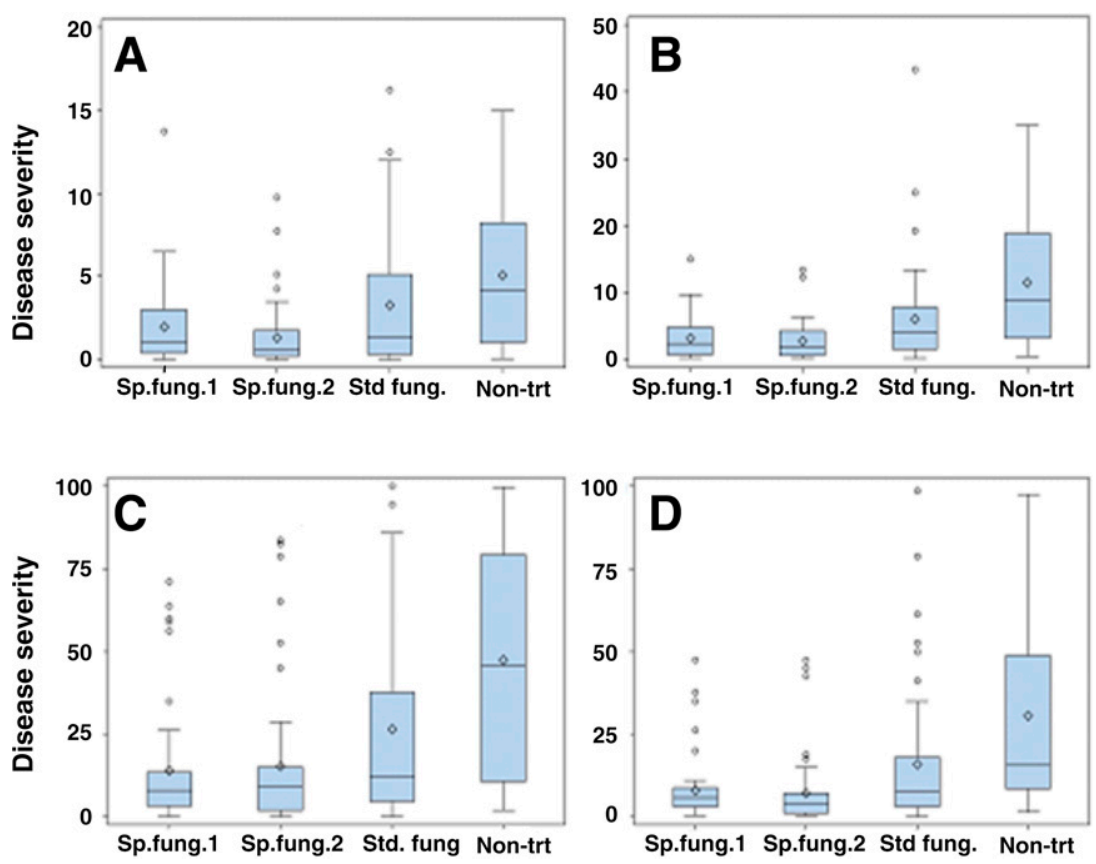

Fig. 2. Box plots for potato early blight percent severity distribution at A, week 6; B, week 7; C, week 8; and D, week 9 representing the tuber initiation and tuber bulking growth stage across 12 study trials. The $x$ axes represent the treatments and y axes represent the nonlog-transformed percent disease severity. Sp, Std, nontrt, and fung = abbreviations for specialty, standard, nontreated, and fungicide, respectively. 
development of pathogen resistance and the high costs of single-site specific fungicides reported in literature, it is common for growers to incorporate specialty fungicides in rotation with fungicides in other FRAC groups for early blight management. In the studies reported here, superior control of overall early blight severity averaged for 11-week assessments (28 to 30\% improvement) was obtained with specialty fungicides when applied in rotation with standard fungicides relative to standard protectant fungicides used alone. The increased performance may be due to the effective rotation of expensive specialty fungicides with standard fungicides. The results reported here are in agreement with earlier research (Horsfield et al. 2010; Secor and Gudmestad 1999). It is likely that the improved performance of specialty fungicides incorporated in fungicide rotational program compared with that of protectants applied alone is that site-specific fungicides may compensate for the efficacy deficiencies of a standard protectant fungicides under conditions of intense disease pressure.

Depending on early blight intensity, crop growth stage affected, and favorable conditions for disease development, tuber yields may be reduced (Franc and Christ 2001; Stevenson et al. 2007). Our yield analysis demonstrated significant differences among all fungicides examined. Yield losses due to early blight of up to $20 \%$ have been reported and frequent fungicide application can mitigate much of this loss (Stevenson et al. 2007). Results from the current studies clearly demonstrate that the programs incorporating specialty fungicides used here can contribute to significant yield increases $(P=0.03)$ when compared with standard fungicides. This clearly demonstrates that the comprehensive effect (measured across 12 trials) of specialty fungicides incorporated into a foliar fungicide program against early blight has long-term crop benefits, such as increased yield.

Fungicide efficacies were monitored by measuring early blight progress against time (11 weeks) through the entire growing season. Early blight progress is usually related to age of the plant, with young, immature plants showing resistance and old, senescing plants having high susceptibility to disease (Pschedit and Stevenson 1988; Rotem 1981; Shtienberg et al. 1996). Repeated-measure analysis for early blight weekly assessment demonstrated that treatment and week-treatment interaction factors have significant effects on disease severity. This indicates that treatments and their interaction with time (week) may have influenced early blight severity results. To support this argument, different potato growth stages related to disease progress and fungicide applications were assessed. Compared with the nontreated control, specialty fungicides incorporated into fungicide application programs significantly improved the control of early blight severity during all three crop growth stages measured. This demonstrates that the specialtygroup fungicides provide superior disease control and that the high yield response is not by chance but, rather, due to the efficacy of fungicides applied. Also, there was no significant difference observed between two specialty fungicide groups in terms of overall disease, yield, and growth stage effects (all 11 weeks), indicating that specialty fungicides may play an effective role in managing early blight during the growing season.

The results reported here demonstrate that, when compared with a standard protectant foliar fungicide program, group 2 specialty fungicides provided significant early blight control during vegetative growth initiation to maturation stages of potato. Our findings differ from previous research conducted over five growing seasons, which indicated that foliar fungicide applications were not required during the vegetative growth of potato (Shtienberg et al. 1996). Failure to prolong the onset of early blight during vegetative growth of potato results in loss of green area of the leaf, thereby affecting the plant's ability to synthesize and store tuber constituents (Horsfield et al. 2010). The studies reported here demonstrate that significant increases in yield can be achieved when specialty fungicide application programs are used compared with when standard protectant fungicides are applied alone. However, when compared with standard fungicides, a group 1 specialty fungicide program did not significantly reduce early blight during vegetative growth initiation and flowering stage of potato crop. Nevertheless, application of group 1 specialty fungicides did significantly increase yields compared with standard fungicides. This may be due to the QoI ability to delay leaf senescence and improve yields under disease pressure (Kildea et al. 2010; McCartney et al. 2007; Thygesen et al. 2009). All three fungicide treatments provided significant early blight control compared with nontreated control treatments during tuber initiation and bulking, indicating that this stage of potato crop growth is critical for improved disease control. This was substantiated with both specialty fungicide groups and standard fungicide treatments, which provided significant yield increases when compared with the nontreated check. Our findings are consistent with previous studies, where maximum early blight pressure was reported to occur late in the season on senescing plants and which concluded that fungicide applications should be most effective during this period (Holm et al. 2003; Horsfield et al. 2010; Shtienberg et al. 1996).

In conclusion, the fungicide programs incorporating specialty products were most effective in managing early blight and improving tuber yields in North Dakota and Minnesota. Currently, potato growers cannot totally rely on the standard fungicide applications alone because they are less effective when compared with foliar fungicide programs where specialty fungicides are incorporated. However, it is critical to safeguard standard fungicides because the current intensive rate of application may exert selection pressure on A. solani, reducing their efficacy, and this would prove to be a significant loss to the potato growers. Although multisite protectant fungicides have a low risk of resistance development compared with single-site specific fungicides, temporal resistance to chlorothalonil in A. solani has been reported (Holm et al. 2003). Due to the absence of fully resistant cultivars, results of our studies demonstrate the advantage and the importance of fungicide rotational programs incorporating specialty and standard fungicides for early blight management. Future research should focus on defining the precise environmental conditions that influence early blight development to facilitate the development of predictive models that

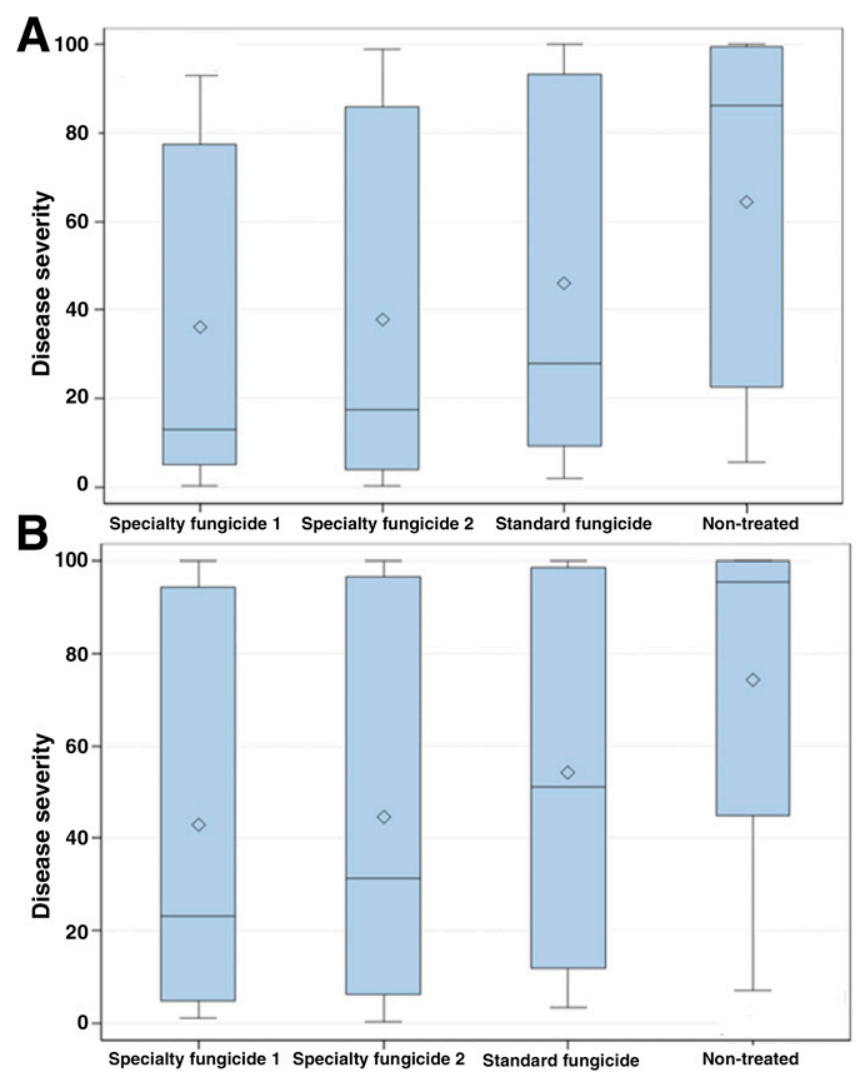

Fig. 3. Box plots for potato early blight percent severity distribution at A, week 10 to B, week 11 representing the tuber maturation stage of the potato crop across 12 study trials. The $x$ axes represent the treatments and $y$ axes represent the nonlogtransformed percent disease severity. Diamond and horizontal lines for box plots represent mean and median values, respectively. 
would assist potato growers in determining when specialty sitespecific fungicide applications are warranted.

\section{Literature Cited}

Ahmed, I., Sutton, A. J., and Riley, R. D. 2012. Assessment of publication bias, selection bias, and unavailable data in meta-analyses using individual participant data: A database survey. Br. Med. J. (Clin. Res. Ed.) 344:d7762.

Bohl, W. H., and Johnson, S. B. 2010. Commercial potato production in North America. Extension Section of the Potato Association of America 57:267.

Franc, G. D., and Christ, B. J. 2001. Early blight. Pages 22-23 in: Compendium of Potato Diseases. W. R. Stevenson, R. Loria, G. D. Franc, and G. D. Weingartner, eds. American Phytopathological Society, St. Paul, MN.

Gudmestad, N. C., Arabiat, S., Miller, J. S., and Pasche, J. S. 2013. Prevalence and impact of SDHI fungicide resistance in Alternaria solani. Plant Dis. 97:952-960.

Harrison, M. D., and Venette, J. R. 1970. Chemical control of potato early blight and its effect on potato yield. Am. Potato J. 47:81-86.

Holm, A. L., Rivera, V. V., Secor, G. A., and Gudmestad, N. C. 2003. Temporal sensitivity of Alternaria solani to foliar fungicides. Am. J. Potato Res. 80:33-40.

Horsfield, A., Wicks, T., Davies, K., Wilson, D., and Paton, S. 2010. Effect of fungicide use strategies on the control of early blight (Alternaria solani) and potato yield. Australas. Plant Pathol. 39:368-375.

Kiær, L., Skovgaard, I. B., and Østergård, H. 2006. Meta-analysis is a powerful tool to summarize variety mixture effects exemplified by grain yield and weed suppression of spring barley. Cereal crop diversity: Implications for production and products. In: SUSVAR Proc. 2006, La Besse, France.

Kildea, S., Dunne, B., Mullins, E., Cooke, L. R., Mercer, P. C., and O'Sullivan, E. 2010. Pyraclostrobin reduces germ tube growth of QoI-resistant Mycosphaerella graminicola pycnidiospores and the severity of Septoria tritici blotch on winter wheat. Plant Pathol. J. 59:1091-1098.

Konstantopoulos, S. 2006. Fixed and mixed effects models in meta-analysis. Discuss. Pap. No. 2198. The Institute for the Study of Labor, Bonn, Germany.

Madden, L. V., and Paul, P. A. 2011. Meta-analysis for evidence synthesis in plant pathology: An overview. Phytopathology 101:16-30.

Mallik, I., Arabiat, S., Pasche, J. S., Bolton, M. D., Patel, J. S., and Gudmestad, N. C. 2014. Molecular characterization and detection of mutations associated with resistance to succinate dehydrogenase-inhibiting fungicides in Alternaria solani. Phytopathology 104:40-49.

McCartney, C., Mercer, P. C., Cooke, L. R., and Fraaije, B. A. 2007. Effects of a strobilurin-based spray programme on disease control, green leaf area, yield and development of fungicide-resistance in Mycosphaerella graminicola in Northern Ireland. Crop Prot. 26:1272-1280.

Means, B., Toyama, Y., Murphy, R., Bakia, M., and Jones, K. 2009. Evaluation of Evidence-Based Practices in Online Learning: A Meta-Analysis and Review of Online Learning Studies. U.S. Department of Education, Office of Planning, Evaluation, and Policy Development, Washington, DC.

Nelson, M. E., Gent, D. H., and Grove, G. G. 2015. Meta-analysis reveals a critical period for management of powdery mildew on hop cones. Plant Dis. 99: 632-640.

Ngugi, H. K., Esker, P. D., and Scherm, H. 2011. Meta-analysis to determine the effects of plant disease management measures: Review and case studies on soybean and apple. Phytopathology 101:31-41.
O'Hara, R. B., and Kotze, D. J. 2010. Do not log-transform count data. Methods Ecol. Evol. 1:118-122.

Olanya, O. M., Honeycutt, C. W., Larkin, R. P., Griffin, T. S., He, Z., and Halloran, J. M. 2009. The effect of cropping systems and irrigation management on development of potato early blight. J. Gen. Plant Pathol. 75:267-275.

Pasche, J. S., and Gudmestad, N. C. 2008. Prevalence, competitive fitness and impact of the F129L mutation in Alternaria solani in the United States. Crop Prot. 27:427-435.

Pasche, J. S., Wharam, C., and Gudmestad, N. C. 2004. Shift in sensitivity of Alternaria solani in response to QoI fungicides. Plant Dis. 88:181-187.

Pscheidt, J. W., and Stevenson, W. R. 1988. The critical period for control of early blight (Alternaria solani) of potato. Am. Potato J. 65:425-438.

Pufulete, M., Higgins, J. P. T., Rogers, C. A., Dreyer, L., Hollingworth, W., Dayer, M., Nightingale, A., McDonagh, T., and Reeves, B. C. 2014. Protocol for a systematic review and individual participant data meta-analysis of B-type natriuretic peptide-guided therapy for heart failure. Syst. Rev. 3:41.

Riley, R. D., Lambert, P. C., and Abo-Zaid, G. 2010. Meta-analysis of individual participant data: Rationale, conduct, and reporting. Br. Med. J. (Clin. Res. Ed.) 340:c221.

Rotem, J. 1981. Fungal diseases of potato and tomato in the Negev region. Plant Dis. 65:315-318.

Secor, G. A., and Gudmestad, N. C. 1999. Managing fungal diseases of potato. Can. J. Plant Pathol. 21:213-221.

Shtienberg, D., Blachinsky, D., Ben-Hador, G., and Dinor, A. 1996. Effects of growing season and fungicide type on the development of Alternaria solani and on potato yield. Plant Dis. 80:994-998.

Stevenson, W. R., and James, R. V. 1999. Evaluation of fungicides to control early blight and late blight of potato-Hancock, 1998. Fungic. Nematic. Tests 54: 212-213.

Stevenson, W. R., James, R. V., Inglis, D. A., Johnson, D. A., Schotzko, R. T., and Thornton, R. E. 2007. Fungicide spray programs for Defender, a new potato cultivar with resistance to late blight and early blight. Plant Dis. 91:1327-1336.

Stewart, G. B., Altman, D. G., Askie, L. M., Duley, L., Simmonds, M. C., and Stewart, L. A. 2012. Statistical analysis of individual participant data metaanalyses: A comparison of methods and recommendations for practice. PLoS One 7:e46042

Stewart, L. A., and Parmar, M. K. 1993. Meta-analysis of the literature or of individual patient data: Is there a difference? Lancet 341:418-422.

Stewart, L. A., and Tierney, J. F. 2002. To IPD or not to IPD? Advantages and disadvantages of systematic reviews using individual patient data. Eval. Health Prof. 25:76-97.

Sung, Y. J., Schwander, K., Arnett, D. K., Kardia, S. L. R., Rankinen, T., Bouchard, C., Boerwinkle, E., Hunt, S. C., and Rao, D. C. 2014. An empirical comparison of meta-analysis and mega-analysis of individual participan data for identifying gene-environment interactions. Genet. Epidemiol. 38:369-378.

Thomas, D., Radji, S., and Benedetti, A. 2014. Systematic review of methods for individual patient data meta- analysis with binary outcomes. Br. Med. J. (Clin. Res. Ed.) 14:79.

Thygesen, K., Jørgensen, L. N., Jensen, K. S., and Munk, L. 2009. Spatial and temporal impact of fungicide spray strategies on fungicide sensitivity of Mycosphaerella graminicola in winter wheat. Eur. J. Plant Pathol. 123: 435-447. 